\title{
Association between objectively evaluated physical activity and sedentary behavior and screen time in primary school children
}

\author{
Chiaki Tanaka ${ }^{*}$, Maki Tanaka², Masayuki Okuda ${ }^{3}$, Shigeru Inoue ${ }^{4}$, Tomoko Aoyama $^{5}$ and Shigeho Tanaka ${ }^{5}$
}

\begin{abstract}
Background: Even when meeting guidelines for physical activity (PA), considerable sedentary time may be included. This study in primary school children investigated the relationships between objectively evaluated sedentary and PA times at different intensities using triaxial accelerometry that discriminated between ambulatory and non-ambulatory PA. The relationships between subjectively evaluated screen time (i.e. time spent viewing television and videos, playing electronic games, and using personal computers) and objectively evaluated sedentary and PA times were examined.
\end{abstract}

Methods: Objectively evaluated sedentary and PA times were assessed for 7 consecutive days using a triaxial accelerometer (Active style Pro: HJA-350IT) in 426 first to sixth grade girls and boys. Metabolic equivalents [METs] were used to categorize the minutes of sedentary time ( $\leq 1.5 \mathrm{METs}$ ), light PA (LPA, 1.6-2.9 METs), moderate-to-vigorous PA (MVPA, $\geq 3.0 \mathrm{METs}$ ) and vigorous PA (VPA, $\geq 6.0 \mathrm{METs}$ ). The physical activity level (PAL) was calculated using the mean MET value. Subjectively evaluated screen time behaviors were self-reported by participants and parents acting together. The associations between PA and sedentary and screen time variables were examined using partial correlation analyses.

Results: After adjustment for age, body weight and wearing time, objectively evaluated sedentary time correlated strongly with non-ambulatory and total LPA and PAL, moderately with ambulatory LPA, non-ambulatory or total MVPA, and weakly with ambulatory MVPA, ambulatory, non-ambulatory or total VPA. Subjectively evaluated screen time was not associated significantly with objectively evaluated sedentary and PA times or PAL. On average, each reduction of 30 min in daily sedentary time was associated with 6 or 23 min more of MVPA or LPA, respectively.

Conclusions: These findings show that higher daily sedentary time may be compensated mainly by lower LPA, while the association between sedentary time and MVPA was moderate. Therefore, improving MVPA and reducing sedentary time are important in primary school children.

Keywords: Exercise, Ambulatory activity, Non-ambulatory activity, Sitting, Accelerometer, Screen time

\section{Background}

The World Health Organization guidelines on physical activity (PA) recommend at least 60 min every day of

\footnotetext{
*Correspondence: c-tanaka@obirin.ac.jp

1 Division of Integrated Sciences, J. F. Oberlin University, 3758

Tokiwamachi, Machida, Tokyo 194-0294, Japan

Full list of author information is available at the end of the article
}

moderate-to-vigorous physical activity (MVPA) in order to benefit the health of children and adolescents [1]. However, considerable sedentary time can be accumulated even when these PA guidelines are met. For example, Marshall et al. [2] reported that clusters of UK and USA adolescents of both genders had higher than average levels of PA, but also increased levels of screen-based sedentary behavior or sedentary socializing activities. 
Sedentary behavior is usually defined as behaviors carried out in a seated or reclining position with an energy cost of $\leq 1.5$ METs [3]. A previous systematic review of the relationship between sedentary time or sedentary behavior and health-related outcomes in children and adolescences showed that long periods of sedentary activity were associated with adverse health outcomes [4-7]. Recently, guidelines for sedentary behavior in children and adolescents have been published in several countries [8-10].

Whether or not more time spent in MVPA is associated with higher physical activity level (PAL) remains an interesting question. One of the first studies to examine this possibility was carried out in adults [11]. A multiple regression analysis of the proportion of time spent on moderate or high intensity activities showed that only moderate intensity activity was a significant predictor of PAL $\left(\mathrm{r}^{2}=0.51\right)$, while the proportions of low and moderate intensity activities influenced total energy expenditure. Recently, Pearson et al. [12] reviewed several observational studies that examined the association between PA and sedentary behavior or sedentary time in young people $(<18$ years), and showed only a weak negative association. However, only a small number of studies have examined the associations between objectively evaluated PA and sedentary time [13].

Previous studies proposed using prediction models of metabolic equivalents (METs) for children with accelerometers. The slope and intercept of ambulatory activities in a predictive model such as walking and running are different from those of non-ambulatory activities, like playing games, cleaning, playing with blocks, tossing a ball, and aerobic dance [14-17]. Based on the variability in accelerometer counts, Hikihara et al. [18] showed a discrimination between ambulatory activities, such as continuous walking or jogging and non-ambulatory activities, including lifestyle activity. Our previous study in primary school children reported that ambulatory light PA (LPA) and MVPA and non-ambulatory LPA were lower in the summer vacation than during the school year in both genders [19]. We also observed that nonambulatory MVPA in girls was significantly lower during the summer vacation than in the school year. Another study in preschool children showed that $25 \mathrm{~m}$ run speed, skill-related physical fitness total Z-score, and total physical fitness Z-score (health-related and skill-related physical fitness total Z-score) correlated positively with the time spent in ambulatory activity [20]. Moreover, thin preschool children spent significantly less time engaged in ambulatory PA than normal-weight or overweight children [21]. Although the contribution of ambulatory and non-ambulatory PAs to health outcomes in children has not been well established [20,21], physical fitness and weight status in children correlated to the types of PA, MVPA was shown to make up approximately $40-45 \%$ of non-ambulatory activity in primary school boys and girls in the school year [19]. Therefore, ambulatory and non-ambulatory PAs may have different effects on the relationships between PAs and sedentary behavior (SB). The objective of the present study was to examine the association between PA intensities and sedentary time in 6-12 year-old Japanese primary school children, using objective accelerometer data for PA that discriminated between non-ambulatory or ambulatory PA. We also examined the contribution of reported screen time to total sedentary and PA times.

\section{Methods}

Our convenience sample included Japanese primary school children from 14 primary schools in urban areas of Tokyo and Kyoto. The participants were invited to participate in the study at their school using leaflets, such as a newsletter. Informed consent was obtained from all participants, and the Ethical Committee of J. F. Oberlin University approved the study protocol (Receipt Number: 12023). All participations and their parents consented to publication of the data. The data of anthropometric measurements, sedentary time, and PA were collected from June 2012 to January 2015 during the school year. The initial sample comprised 569 participants with 143 children subsequently being withdrawn because of: accelerometer data not conforming with the study criteria (see below) [ $\mathrm{n}=95]$, revocation of the agreement $[\mathrm{n}=7]$, history of conditions affecting PA such as respiratory disease or heart disease $[\mathrm{n}=25]$, no questionnaire data [ $\mathrm{n}=15]$, and belonging to a different ethnic group $[\mathrm{n}=1]$. Data analysis was carried out on the remaining 426 children. These children, except those who revoked the agreement $[n=7]$, participated in the study, but their data were excluded from the analyses. There was no significant difference in age, relative weight and gender proportion between the study group and children withdrawn from the analyses.

\section{Objective measurement of sedentary time and physical activity}

Habitual sedentary time and PA were measured using a triaxial accelerometer (Active style Pro HJA-350IT, Omron Healthcare, Kyoto; dimensions $74 \times 46 \times 34 \mathrm{~mm}$ and weight $60 \mathrm{~g}$ including batteries). The device is described in detail elsewhere [18]. The participants wore the accelerometer on the left side of the waist at school. We calculated the synthetic acceleration in all three axes using signals before and after high-pass filtering. The ratio of unfiltered to filtered acceleration was then calculated to identify non-ambulatory activities (e.g., playing 
games, playing with blocks, tossing a ball, and cleaning and clearing away) and ambulatory activities (e.g., walking and running). When the ratio of unfiltered to filtered synthetic acceleration was 1.12 , the rate of correct discrimination between non-ambulatory and ambulatory activities was excellent, with a mean of $99.1 \%$ [18]. The acceleration signals were calculated as the mean of the absolute values of accelerometer output in each axis over $10 \mathrm{~s}$ epochs at the middle of each activity. The data were expressed as variables of acceleration output. Because the predictive equations used for the Active style Pro were established in adults, the values of metabolic equivalent (MET) values recorded by the accelerometer are overestimated in primary school children [18]. We therefore used the following conversion equations for primary school children, based on the results of Hikihara et al. [18].

Ambulatory activities:

$0.6237 \times$ MET value of Active style Pro +0.2411

Non-ambulatory activities:

$0.6145 \times$ MET value of Active style Pro + 0.5573

Sedentary time and PA were monitored continuously for 7 days. The participants were requested to wear the devices at all times, except under special circumstances, such as dressing and bathing. In fact, many participants wore the accelerometer during sleep. Because sleep and sedentary time cannot be discriminated we analyzed data collected between 7:00 and 21:00 to exclude sleep time. We included days in which $>600 \mathrm{~min}(10 \mathrm{~h})$ of wearing time had accrued. Periods with $>60$ min of consecutive "non-wearing time" were as classified as non-wearing time. Penpraze et al. [22] and Cliff et al. [23] suggested at least 3 days were required for reliable PA monitoring in young children. Participants with data from at least 2 weekdays and at least 1 weekend day were included in the analysis.

\section{Self-reported measures}

Time spent viewing television and videos, playing electronic games and using a personal computer was assessed by a questionnaire completed jointly by the children and their parents. The children and parents were asked the following two questions: "How many hours of television and video movies (except at school) does the child usually watch? (a) in a school day or (b) in a non-school day $-0,30 \mathrm{~min}, 1,2,3$, 4, or $>5$ h; and "How many hours in a single day does the child usually use a personal computer or play electronic games (including television, personal computer, portable game machines such as mobile phones at home and friends' homes including arcade games, etc.)? (a) in a school day or (b) a non-school day0 , 30 min, 1, 1.5, 2, 2.5, or $>3 \mathrm{~h}$.

\section{Anthropometric measurements}

Body height and weight were measured without shoes, but with clothing to the nearest $0.1 \mathrm{~cm}$ and $0.1 \mathrm{~kg}$, respectively. Net body weight was calculated as the weight of clothing subtracted from the measured body weight. BMI (body mass index) was calculated as weight in kilograms divided by height in meters squared. Weight status was classified as normal weight, overweight/obese, or thin using the Japanese cut-offs for weight based on national reference data for Japanese children [24].

Relative weight was calculated as [body weight $(\mathrm{kg})$ - standard weight for gender, age, and height $(\mathrm{kg})] /$ standard weight $(\mathrm{kg}) \times 100(\%)$

$$
\begin{aligned}
& * \text { standard weight }(\mathrm{kg}) \\
& \quad=\mathrm{a} \times \text { measured body height }(\mathrm{cm})-\mathrm{b}
\end{aligned}
$$

$a$ and $b$ are gender- and age-specific.

The cut-off values for weight categories were: overweight/obesity combined, $\geq+20 \%$; normal weight, -20 to $+20 \%$; thin, $\leq-20 \%$.

\section{Analyses}

The time spent in sedentary and each PA intensity each day was calculated using METs for each individual: average number of weekday and weekend minutes spent in sedentary time (METs $\leq 1.5$ ), LPA (METs 1.6-2.9), MVPA (METs $\geq 3.0$ ) and VPA (METs $\geq 6.0$ ). The mean weekly values were then calculated. Time spent viewing TV and video games was calculated as (1) $0 \mathrm{~min}$, (2) 30 min, (3) 1 h, (4) 2 h, (5) 3 h, (6) 4 h, (7) 5 h. Time using a personal computer, or playing electronic games was calculated as (1) $0 \mathrm{~min},(2) 30 \mathrm{~min}$, (3) $1 \mathrm{~h}$, (4) $1.5 \mathrm{~h}$, (5) $2 \mathrm{~h}$, (6) $2.5 \mathrm{~h}$, or (7) $3 \mathrm{~h}$. For the objective and subjective data, the mean values were calculated by weighting for 5 weekdays and 2 weekend days [Weighted data $=(($ mean for weekdays $\times 5)+($ mean for weekend days $\times 2)) / 7]$. PA assessed by the accelerometer was presented as: (1) PA states for ambulatory activity or non-ambulatory activity in intensity-specific categories (LPA, MVPA, and VPA); and (2) PAL, total energy expenditure ( $\mathrm{kcal} /$ day) divided by basal metabolic rate $(\mathrm{kcal} /$ day), calculated using the mean value of METs.

The relationship between two variables was examined using partial correlation analysis controlled for gender, age, body weight, and wearing time. A simple linear stepwise regression analysis was used to obtain prediction equations. The dependent variables were sedentary time, LPA, and MVPA and the independent variables sedentary time, LPA, MVPA or VPA, and gender, age, body weight, and wearing time. The results are shown as mean \pm standard deviation (SD). The statistical analyses were performed using IBM SPSS statistics 20.0 for Windows (IBM Co., Tokyo, 
Japan). All statistical tests were regarded as significant when $p$ values were $\leq 0.05$.

\section{Results}

\section{Characteristics of the study participants}

Table 1 shows the characteristics of the study participants and time spent at sedentary, different intensity levels and total time for ambulatory and non-ambulatory activity, PAL, and subjectively evaluated screen-based sedentary behavior. Five percent of participants were overweight/obese. The duration of accelerometry was considerably greater than the minimum criteria specified (at least 3 days and $10 \mathrm{~h}$ ), with a mean of 6.3 days and $13.4 \mathrm{~h}$, respectively. The percentage of children with $>2 \mathrm{~h} /$ day of screen time was $59.8 \%$. The percentages of each response category (1-7 corresponding to $0,30 \mathrm{~min}, 1,2$, 3,4 , or $>5 \mathrm{~h}$, respectively) for television and video viewing time in a school or non-school day were $6.9 \%$ (school day) and $0.7 \%$ (non-school day) in category 1; 13.8 and Table 1 Physical characteristics and determinants at base-
line of the participants

\begin{tabular}{|c|c|c|}
\hline \multirow[t]{2}{*}{ Variables } & \multicolumn{2}{|l|}{$n=426$} \\
\hline & Average & SD \\
\hline Age (year) & $9.3 \pm 1.6$ & \\
\hline Height (cm) & $132.3 \pm 10.7$ & \\
\hline Weight (kg) & $29.0 \pm 7.5$ & \\
\hline Body mass index $\left(\mathrm{kg} / \mathrm{m}^{2}\right)$ & $16.3 \pm 2.2$ & \\
\hline Relative weight (\%) & $-2.9 \pm 11.9$ & \\
\hline Sedentary behaviour (min/day) & $363 \pm 62$ & \\
\hline \multicolumn{3}{|l|}{ LPA (min/day) } \\
\hline Ambulatory & $105 \pm 19$ & \\
\hline Non-ambulatory & $225 \pm 43$ & \\
\hline Total time & $360 \pm 50$ & \\
\hline \multicolumn{3}{|l|}{ MVPA (min/day) } \\
\hline Ambulatory & $39 \pm 15$ & \\
\hline Non-ambulatory & $28 \pm 9$ & \\
\hline Total time & $68 \pm 21$ & \\
\hline \multicolumn{3}{|l|}{ VPA (min/day) } \\
\hline Ambulatory & $5 \pm 3$ & \\
\hline Non-ambulatory & $1 \pm 1$ & \\
\hline Total time & $6 \pm 4$ & \\
\hline Physical activity level & $1.74 \pm 0.07$ & \\
\hline Wearing time (min/day) & $802 \pm 34$ & \\
\hline Wearing day (days) & $6.3 \pm 1.0$ & \\
\hline $\begin{array}{l}\text { Television and video viewing time (min/day) } \\
(\mathrm{n}=420)\end{array}$ & $110 \pm 60$ & \\
\hline $\begin{array}{l}\text { Time spent playing electronic games and using } \\
\text { personal computers (min/day) }(n=419)\end{array}$ & $36 \pm 37$ & \\
\hline Total screen time (min/day) $(n=415)$ & $146 \pm 80$ & \\
\hline
\end{tabular}

LPA light physical activity, MVPA moderate-to-vigorous physical activity, VPA vigorous physical activity
$2.4 \%$ in category $2 ; 33.1$ and $14.3 \%$ in category $3 ; 33.1$ and $32.6 \%$ in category $4 ; 9.3$ and $26.9 \%$ in category $5 ; 2.1$ and $14.5 \%$ in category 6 ; and 1.7 and $8.6 \%$ in category 7 . The corresponding percentages in games and personal computer time (1-7 corresponding to $0,30 \mathrm{~min}, 1,1.5$, $2,2.5$, or $>3 \mathrm{~h}$, respectively) were $46.1 \%$ (school day) and $25.1 \%$ (non-school day) in category $1 ; 28.2$ and $25.8 \%$ in category 2; 15.5 and $22.9 \%$ in category $3 ; 6.0$ and $6.9 \%$ in category $4 ; 3.6$ and $11.9 \%$ in category $5 ; 0.2$ and $2.1 \%$ in category 6 ; and 0.5 or $5.3 \%$ in category 7 .

Table 2 shows the partial correlation between duration of objectively evaluated sedentary time, each intensity and type of PA, PAL, and screen time. After adjustment for age, gender, body weight, and wearing time, objectively evaluated sedentary time correlated strongly with non-ambulatory and total LPA and PAL, moderately with ambulatory LPA, non-ambulatory and total MVPA, and weakly with ambulatory MVPA and ambulatory, nonambulatory and total VPA. Screen time was not associated significantly with objectively evaluated sedentary time, PAs, or PAL.

The results of the stepwise linear regression analysis (Table 3) showed that on average, each additional 10 min each day of MVPA or LPA was associated with 18 and 12 min less of objectively evaluated sedentary time, respectively. In contrast, each $30 \mathrm{~min}$ reduction in daily sedentary time was associated with 6 or 23 min more of objectively evaluated MVPA or LPA.

\section{Discussion}

This study examined the associations between sedentary time and PAL or PAs classified as either ambulatory or non-ambulatory using triaxial accelerometry in primary school Japanese children. We showed significant associations between objectively evaluated sedentary time and PAL or PAs. In particular, non-ambulatory and total LPA correlated strongly with sedentary time, with the increase in sedentary time being compensated mainly by decreased LPA. On the other hand, there was only a moderate degree of correlation between MVPA and sedentary time, while no association was found between subjectively evaluated screen time and objectively evaluated sedentary time, PAs or PAL. These findings indicate that improvement in MVPA and decrease in sedentary time may be independent of each other to some degree in primary school children.

PAL for level II (moderate) and level III (high) in Japanese individuals is categorized as 1.60 and 1.80 for $8-9$ years and 1.65 and 1.85 for $10-11$ years, respectively. These Dietary Reference Intakes for Japanese-2015are based on the doubly labeled water method [25]. The mean value of PAL (1.74) in the sample of the present study $(9.3 \pm 1.6$ years) was categorized as level II 
Table 2 Partial correlation coefficients between daily sedentary behavior and physical activity

\begin{tabular}{|c|c|c|c|c|c|}
\hline Variables & $\begin{array}{l}\text { Sedentary time } \\
\text { (min/day) }\end{array}$ & LPA (min/day) & MVPA (min/day) & VPA (min/day) & $\begin{array}{l}\text { Physical activity } \\
\text { level }\end{array}$ \\
\hline Sedentary time (min/day) & - & - & - & - & $-0.87^{*}$ \\
\hline \multicolumn{6}{|l|}{ LPA (min/day) } \\
\hline Ambulatory & $-0.58^{*}$ & $0.49^{*}$ & $0.44^{*}$ & $0.24^{*}$ & $0.55^{*}$ \\
\hline Non-ambulatory & $-0.81^{*}$ & $0.91^{*}$ & $0.18^{*}$ & -0.04 & $0.52^{*}$ \\
\hline Total time & $-0.95^{*}$ & - & $0.34^{*}$ & 0.06 & $0.68^{*}$ \\
\hline \multicolumn{6}{|l|}{ MVPA (min/day) } \\
\hline Ambulatory & $-0.41^{*}$ & $0.13^{*}$ & $0.90^{*}$ & $0.68^{*}$ & $0.74^{*}$ \\
\hline Non-ambulatory & $-0.66^{*}$ & $0.53^{*}$ & $0.72^{*}$ & $0.26^{*}$ & $0.73^{*}$ \\
\hline Total time & $-0.61^{*}$ & $0.34^{*}$ & - & $0.62^{*}$ & $0.89^{*}$ \\
\hline \multicolumn{6}{|l|}{ VPA (min/day) } \\
\hline Ambulatory & $-0.24^{*}$ & 0.05 & $0.58^{*}$ & $0.97^{*}$ & $0.58^{*}$ \\
\hline Non-ambulatory & $-0.26^{*}$ & 0.08 & $0.57^{*}$ & $0.82^{*}$ & $0.57^{*}$ \\
\hline Total time & $-0.27^{*}$ & 0.06 & $0.62^{*}$ & - & $0.62^{*}$ \\
\hline $\begin{array}{l}\text { Television and video viewing time (min/day) } \\
\qquad(n=420)\end{array}$ & 0.02 & -0.06 & 0.09 & 0.04 & 0.02 \\
\hline $\begin{array}{l}\text { Time spent playing electronic games and } \\
\text { using personal computers (min/day) } \\
(n=419)\end{array}$ & 0.06 & -0.06 & -0.02 & -0.03 & -0.05 \\
\hline Total screen time (min/day) $(n=415)$ & 0.05 & -0.08 & 0.04 & 0.01 & -0.02 \\
\hline
\end{tabular}

Adjusted variables: age, sex, body weight and wearing time

LPA light physical activity, MVPA moderate-to-vigorous physical activity, VPA vigorous physical activity

${ }^{*} \mathrm{p}<0.05$

Table 3 Prediction equations for sedentary behavior or moderate-to-vigorous physical activity

\begin{tabular}{|c|c|c|c|}
\hline Prediction equations & Adjusted $\mathrm{R}^{2}$ & SEE & $p$ value \\
\hline $\begin{array}{l}\text { Sedentary behavior }(\mathrm{min} / \text { day })=-64(50)-1.83(0.12) * \mathrm{MVPA}(\mathrm{min} / \text { day })+0.606(0.057) * \text { wearing time }(\mathrm{min} / \\
\text { day })-19.7(4.4) * \text { sex }+6.88(1.74) * \text { age }(\text { year })+1.06(0.35) * \text { body weight }(\mathrm{kg})\end{array}$ & 0.60 & 39.6 & $<0.001$ \\
\hline $\begin{array}{l}\text { Sedentary behavior }(\mathrm{min} / \text { day })=-111(19)-1.16(0.02) * \mathrm{LPA}(\mathrm{min} / \text { day })+1.04(0.02) * \text { wearing time }(\mathrm{min} / \text { day })+18.5 \\
\left.(1.6){ }^{*} \mathrm{sex}+3.30(0.55) * \text { age (year }\right)\end{array}$ & 0.94 & 15.7 & $<0.001$ \\
\hline $\begin{array}{l}\text { Sedentary behavior }(\mathrm{min} / \text { day })=-271(59)-3.75(0.59) * \mathrm{VPA}(\mathrm{min} / \text { day })+0.60(0.07) * \text { wearing time }(\mathrm{min} / \text { day })+15.48 \\
(2.05) * \text { age }(\text { year })+1.13(0.44) * \text { body weight }(\mathrm{kg})\end{array}$ & 0.40 & 48.5 & $<0.001$ \\
\hline $\begin{array}{l}\mathrm{LPA}(\mathrm{min} / \text { day })=-71(16)-0.78(0.01) * \text { sedentary behavior }(\mathrm{min} / \text { day })+0.85(0.02) * \text { wearing times }(\mathrm{min} / \text { day })+15.3 \\
(1.3)^{*} \mathrm{sex}+1.22(0.47) * \text { age }(\text { year })\end{array}$ & 0.93 & 12.9 & $<0.001$ \\
\hline $\begin{array}{l}\mathrm{LPA}(\mathrm{min} / \text { day })=56(49)+0.84(0.11) * \mathrm{MVPA}(\mathrm{min} / \text { day })+0.38(0.06) * \text { wearing time }(\mathrm{min} / \text { day })+20.3(4.3) * \text { sex }-6.61 \\
(1.71) * \text { age }(\text { year })-1.04(0.35) * \text { body weight }(\mathrm{kg})\end{array}$ & 0.39 & 38.8 & $<0.001$ \\
\hline $\begin{array}{l}\text { MVPA }(\min / \text { day })=67(16)-0.20(0.01) * \text { sedentary behavior }(\min / \text { day })+0.14(0.02) * \text { wearing time }(\mathrm{min} / \text { day })-14.9 \\
(1.3) * \text { sex }-1.16(0.48) * \text { age }(\text { year })\end{array}$ & 0.59 & 13.2 & $<0.001$ \\
\hline MVPA $(\min /$ day $)=78(10)+0.13(0.02) * \operatorname{LPA}(\min /$ day $)-18.2(1.6) *$ sex $-3.28(0.55) *$ age (year) & 0.41 & 15.8 & $<0.001$ \\
\hline
\end{tabular}

SEE standard error of estimate, sex: boy: 1, girl: 2, LPA light physical activity, MVPA moderate-to-vigorous physical activity, VPA vigorous physical activity, the values given in parentheses in prediction equations were SEE for each partial regression coefficient

(moderate). Screen time over $2 \mathrm{~h} /$ day was found in $59.8 \%$ of children. Recently, Pearson et al. [12] reviewed several observational studies that had examined the association between PA and objectively evaluated sedentary behavior or screen time in young people ( $<18$ years), and showed only a small, negative association. This suggested that these behaviors did not directly displace one another.

Studies to date have assessed the association between objectively measured PAL, PA intensities, and sedentary time. Several studies [26-29] showed relatively strong and negative correlations between sedentary time or lowintensity PA and total PA such as PAL. On the other hand, some studies reported a negative correlation between sedentary time and MVPA [13, 28, 29], whereas others reported no such association [26, 27]. These discrepancies were probably due to differences in sample characteristics, accelerometry, and cutoffs between sedentary time, LPA, and MVPA. Our results are in agreement 
with some of these previous studies in children and adolescents. When interpreting the differences in results between studies in children and adolescents, differences in the definition or algorism of MVPA and differences in epoch length between studies may have contributed to the conflicting results [30-33]. In contrast to the findings in adults, where PAL can be increased by increasing the amount of time spent on moderate intensity activities and reducing low-intensity activities [11], children and adolescents are characterized by short, intermittent bouts of VPA [34, 35]. The association between sedentary time and MVPA observed in the present study was not seen in previous studies. The associations between sedentary time and MVPA were not significantly different between boys and girls and lower grade and upper grade individuals ( $1-3$ grade boys, $-0.64 ; 1-3$ grade girls, -0.58 ; $4-6$ grade boys, -0.59 ; $4-6$ grade girls, -0.68 ). Therefore, all children were included in our analyses.

In the present study, time spent on screen-based sedentary behavior (TV and video viewing time, $\mathrm{PC}$ and game time, and total screen time) recorded in the questionnaire did not correlate significantly with sedentary time assessed by the accelerometer. Lubans et al. [36] reviewed the validity of self- and proxy-report measures of sedentary behavior estimates of screen time to assess the utility of accelerometers to classify sedentary time in children and adolescents and showed self-reported measures remain largely untested [36]. In the present study, PAs and PAL were not associated with screen time. Herman et al. [13] also showed that neither MVPA nor LPA were associated with screen time in children. Self- and proxyreport measures of sedentary behavior instead provided information about the type of sedentary behavior or context. Studies on the association between screen time and PAs are therefore needed to further understand the complex relationships between sedentary behavior and PAs.

The present study indicated that considerably more time was spent in non-ambulatory LPA than ambulatory LPA. On the other hand, non-ambulatory and ambulatory MVPA minutes were comparable. Previous studies did not, however, discriminate between ambulatory and non-ambulatory PA. Objectively evaluated sedentary time showed a stronger negative correlation with non-ambulatory MVPA or LPA $(r=-0.66$ and -0.81 , respectively) than ambulatory MVPA or LPA ( $\mathrm{r}=-0.41$ and -0.58 , respectively). Although there is only limited evidence on the association between ambulatory and non-ambulatory PAs and health outcome in children $[20,21]$, physical fitness and weight status in children seem to be related to the types of PA. MVPA represents approximately $40-45 \%$ of non-ambulatory activity in primary school boys and girls during the school year [19]. Evidence from the current study also indicates that both ambulatory activity and non-ambulatory activity are important factors in the PA lifestyle of children. Therefore, public health strategies should target LPA and non-ambulatory MVPA to decrease sedentary time and improve overall PA and health in children. These data may be particularly important for providing insights into improving different intensities of PA in children. On average, each additional $10 \mathrm{~min}$ of daily MVPA or LPA was associated with 18 and 12 min less of objectively evaluated sedentary time. Over the course of a week, sedentary time was compensated mainly by higher daily LPA, as indicated by the strong correlation and partial regression coefficient being close to 1.0. Moreover, although the correlation between MVPA and sedentary time was slightly weaker, higher daily MVPA may lead to lower sedentary time and higher total PA to some degree, probably due to concomitant higher levels of LPA. In contrast, each 30 min reduction in daily sedentary time was associated with 6 or 23 min more of objectively evaluated MVPA or LPA. Therefore, the discrepancy in the corresponding durations was larger in the latter case (18 and $12 \mathrm{~min}$ vs. 6 and $23 \mathrm{~min}$ for MVPA and LPA, respectively). The main reason for this observation may be that reduced sedentary time was displaced mainly by LPA and not MVPA, while higher MVPA accompanied LPA, leading to sufficiently lower sedentary time.

There are several methodological points that need to be considered when interpreting our results. Firstly, our sample was not a representative sample of Japanese children. Secondly, the accelerometer is a widely used tool to measure PA, but it cannot assess all PA, such as swimming and cycling. These two points were limitations of the study. The strengths of our study include the use of objective and quantitative measures of sedentary time, classifying ambulatory and non-ambulatory PA, and the use of a sample population of Japanese primary school children from 14 different schools. It should be noted that the data were recorded over a 10-sec epoch, which should be sufficiently sensitive to pick up short bursts of vigorous activity [31,37]. Shorter epoch lengths could be used to better reflect movement patterns of children.

\section{Conclusions}

In Japanese primary school children, objectively evaluated sedentary time correlated strongly with non-ambulatory and total LPA or PAL, moderately with ambulatory LPA, non-ambulatory or total MVPA, and weakly with ambulatory MVPA, ambulatory, non-ambulatory or total VPA, after adjustment for age, gender, body weight and wearing time. Screen time was not associated significantly with objectively evaluated sedentary time, PAs, or PAL. On average, each additional $10 \mathrm{~min}$ of daily MVPA or LPA was associated with 18 or 12 min less of 
objectively evaluated sedentary time. In contrast, each 30 min reduction in daily sedentary time was associated with 6 or 23 min more of objectively evaluated MVPA or LPA. These findings indicate that higher daily sedentary time was compensated by lower LPA, with only a moderate association between sedentary time and MVPA. Taken together, these findings indicate that evaluation of non-ambulatory activity or LPA is important in the overall assessment of PA.

\section{Abbreviations \\ PA: physical activity; SB: sedentary behavior; METs: metabolic equivalents; LPA: light intensity activity; MVPA: moderate-to-vigorous physical activity; VPA: vigorous physical activity; PAL: physical activity level; BMI: body mass index; TV:} television.

\section{Authors' contributions}

CT and ST designed the research. CT, MT, and MO coordinated data collection CT, ST, TA, and MT analyzed the data. CT, MO, SI, and ST discussed the analysis and interpreted the results. CT wrote the paper and had primary responsibility for the final content. All authors reviewed the manuscript critically. All authors read and approved the final manuscript.

\section{Author details \\ ${ }^{1}$ Division of Integrated Sciences, J. F. Oberlin University, 3758 Tokiwamachi, Machida, Tokyo 194-0294, Japan. ${ }^{2}$ Department of Child Education, Kyoto Seibo College, 1 Taya-cho, Fukakusa Fushimi-ku, Kyoto 612-0878, Japan. ${ }^{3}$ Department of Environmental Medicine, Graduate School of Science and Engineering, Yamaguchi University, 1-1-1 Minamikogushi, Ube 755-8505, Japan. ${ }^{4}$ Department of Preventive Medicine and Public Health, Tokyo Medical University, 6-1-1 Shinjuku, Shinjuku-ku, Tokyo 160-8402, Japan. ${ }^{5}$ Depart- ment of Nutrition and Metabolism, National Institute of Health and Nutrition, National Institutes of Biomedical Innovation, Health and Nutrition, 1-23-1 Toyama, Shinjuku-ku, Tokyo 162-8636, Japan.}

\section{Acknowledgements}

The authors would like to thank the participants for their cooperation in the study. We also wish to thank the staff of the National Institute of Health and Nutrition for their help with the experiments. This work was supported by a Grant-in-Aid for Scientific Research (C) (24500832).

\section{Competing interests}

Dr. Shigeho Tanaka received consigned research funds from Omron Healthcare Co., Ltd. The remaining authors declare no competing interests.

\section{Availability of data and materials}

The dataset supporting the conclusions of this article is currently not available in the public domain but may be shared upon request. For further information on the data and materials used in this study please contact the corresponding author.

\section{Ethics approval and consent to participate}

As described in the "Methods", informed consent was obtained from all participants, and the Ethical Committee of J. F. Oberlin University approved the study protocol (Receipt Number: 12023). All participations and their parents consented to publication of the data.

\section{Funding}

This work was supported by a Grant-in-Aid for Scientific Research (C) (24500832).

\section{Publisher's Note}

Springer Nature remains neutral with regard to jurisdictional claims in published maps and institutional affiliations.
Received: 22 May 2016 Accepted: 25 April 2017

Published online: 02 May 2017

\section{References}

1. World Health Organization. 2011. http://www.who.int/dietphysicalactivity/publications/physical-activity-recommendations-5-17years.pdf?ua=1. Accessed 28 Mar 2016.

2. Marshall SJ, Biddle SJH, Sallis JF, et al. Clustering of sedentary behaviors and physical activity among youth: a cross-national study. Pediatr Exerc Sci. 2002;14:401-17.

3. Sedentary Behaviour Research Network. Standardized use of the terms "sedentary" and "sedentary behaviours". Appl Physiol Nutr Metab. 2012;37:540-2.

4. Pate RR, Mitchell JA, Byun W, et al. Sedentary behaviour in youth. Br J Sports Med. 2011;45:906-13.

5. Salmon J, Tremblay MS, Marshall SJ, et al. Health risks, correlates, and interventions to reduce sedentary behavior in young people. Am J Prev Med. 2011:41:197-206.

6. LeBlanc AG, Spence JC, Carson V, et al. Systematic review of sedentary behaviour and health indicators in the early years (aged $0-4$ years). Appl Physiol Nutr Metab. 2012;37:753-72.

7. Tanaka C, Reilly JJ, Huang WY. Longitudinal changes in objectively measured sedentary behaviour and their relationship with adiposity in children and adolescents: systematic review and evidence appraisal. Obes Rev. 2014;15:791-803.

8. Department of Health and Ageing. National physical activity guidelines for Australians. Physical activity recommendations for $0-5$ year olds. Government of Australia: Canberra, 2010. http://www.health.gov.au/ internet/main/publishing.nsf/content/health-pubhlth-strateg-phys-actguidelines. Accessed 28 Mar 2016

9. Start Active Stay Active. Stay Active, Stay Active: A report on physical activity for health from the four home countries' Chief Medical Officers. United Kingdom. 2011. https://www.gov.uk/government/uploads/system/uploads/attachment_data/file/216370/dh_128210.pdf. Accessed 28 Mar 2016.

10. Tremblay MS, Leblanc AG, Carson V, et al. Canadian sedentary behaviour guidelines for the early years (aged 0-4 years). Appl Physiol Nutr Metab. 2012;37:370-91.

11. Westerterp KR. Pattern and intensity of physical activity. Nature 2001:410:539.

12. Pearson N, Braithwaite RE, Biddle SJ, et al. Associations between sedentary behaviour and physical activity in children and adolescents: a metaanalysis. Obes Rev. 2014;15:666-75.

13. Herman KM, Paradis G, Mathieu ME, et al. Association between accelerometer-measured physical activity intensities and sedentary time in 8- to 10-year-old children. Pediatr Exerc Sci. 2014;26:76-85.

14. Tanaka C, Tanaka S, Kawahara J, et al. Triaxial accelerometry for assessment of physical activity in young children. Obesity. 2007;15:1233-41.

15. Freedson P, Pober D, Janz KF. Calibration of accelerometer output for children. Med Sci Sports Exerc. 2005;37(11 Suppl):S523-30.

16. Rowlands AV, Thomas PW, Eston RG, et al. Validation of the RT3 triaxial accelerometer for the assessment of physical activity. Med Sci Sports Exerc. 2004;36:518-24.

17. Puyau MR, Adolph AL, Vohra FA, et al. Prediction of activity energy expenditure using accelerometers in children. Med Sci Sports Exerc 2004;36:1625-31

18. Hikihara Y, Tanaka C, Oshima Y, et al. Prediction models discriminating between nonlocomotive and locomotive activities in children using a triaxial accelerometer with a gravity-removal physical activity classification algorithm. PLoS ONE. 2014;9:e94940.

19. Tanaka C, Reilly JJ, Tanaka M, et al. Seasonal changes in objectively measured sedentary behavior and physical activity in Japanese primary school children. BMC Public Health. 2016;16:969.

20. Tanaka C, Hikihara Y, Ohkawara K, et al. Locomotive and non-locomotive activity as determined by triaxial accelerometry and physical fitness in Japanese preschool children. Pediatr Exerc Sci. 2012;24:420-34. 
21. Tanaka C, Tanaka S. Objectively-measured physical activity and body weight in Japanese pre-schoolers. Ann Hum Biol. 2013;40:541-6.

22. Penpraze V, Reilly JJ, Maclean CM, et al. Monitoring of physical activity in young children: how much is enough? Pediatr Exerc Sci. 2006;18:483-91.

23. Cliff DP, Reilly JJ, Okely AD. Methodological considerations in using accelerometers to assess habitual physical activity in children aged $0-5$ years. J Sci Med Sport. 2009;12:557-67.

24. Ministry of Education, culture, sports, science and technology. Health checkup manual for school children (2015 revision). Japanese Society of School Health, Tokyo; 2015.

25. Ministry of Health, labour and welfare. Dietary reference intakes for Japanese, 2015. 2014. http://www.mhlw.go.jp/file/05-Shingikai10901000-Kenkoukyoku-Soumuka/0000114399.pdf Accessed 5 Apr 2016.

26. Montgomery C, Reilly JJ, Jackson DM, et al. Relation between physical activity and energy expenditure in a representative sample of young children. Am J Clin Nutr. 2004;80:591-6.

27. Hoos MB, Kuipers H, Gerver WJ, et al. Physical activity pattern of children assessed by triaxial accelerometry. Eur J Clin Nutr. 2004:58:1425-8.

28. Ekelund U, Luan J, Sherar LB, International Children's Accelerometry Database (ICAD) Collaborators, et al. Moderate to vigorous physical activity and sedentary time and cardiometabolic risk factors in children and adolescents. JAMA. 2012;307:704-12.

29. Oliver M, Schluter PJ, Rush E, et al. Physical activity, sedentariness, and body fatness in a sample of 6-year-old pacific children. Int J Pediatr Obes. 2011;6:e565-73.

30. Tucker P. The physical activity levels of preschool-aged children: a systematic review. Early Child Res Q. 2008;23:547-58.
31. Vale S, Santos R, Silva P, et al. Preschool children physical activity measurement: importance of epoch length choice. Pediatr Exerc Sci. 2009:21:413-20.

32. Kim Y, Beets MW, Pate RR, et al. The effect of reintegrating actigraph accelerometer counts in preschool children: comparison using different epoch lengths. J Sci Med Sport. 2013;16:129-34

33. Ekelund $U$, Tomkinson $G$, Armstrong N. What proportion of youth are physically active? Measurement issues, levels and recent time trends. $\mathrm{Br}$ J Sports Med. 2011;45:859-65.

34. Bailey RC, Olson J, Pepper SL, et al. The level and tempo of children's physical activities: an observational study. Med Sci Sports Exerc 1995;27:1033-41.

35. Molnár D, Livingstone B. Physical activity in relation to overweight and obesity in children and adolescents. Eur J Pediatr. 2000;159(Suppl 1):S45-55.

36. Lubans DR, Hesketh K, Cliff DP, et al. A systematic review of the validity and reliability of sedentary behaviour measures used with children and adolescents. Obes Rev. 2011:12:781-99.

37. Nilsson A, Ekelund U, Yngve A, et al. Assessing physical activity among children with accelerometers using different time sampling intervals and placements. Pediatr Exerc Sci. 2002;14:87-96.

\section{Submit your next manuscript to BioMed Central and we will help you at every step:}

- We accept pre-submission inquiries

- Our selector tool helps you to find the most relevant journal

- We provide round the clock customer support

- Convenient online submission

- Thorough peer review

- Inclusion in PubMed and all major indexing services

- Maximum visibility for your research

Submit your manuscript at www.biomedcentral.com/submit 